\title{
Effect of remote ischemic preconditioning on renal dysfunction after complex valvular heart surgery: A randomized controlled trial
}

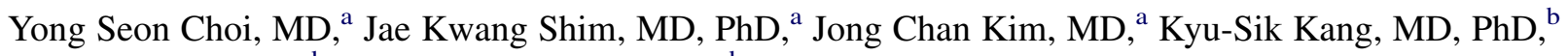 \\ Yong Han Seo, MD, ${ }^{b}$ Ki-Ryang Ahn, MD, PhD, ${ }^{b}$ and Young Lan Kwak, MD, $\mathrm{PhD}^{\mathrm{a}, \mathrm{c}}$
}

\begin{abstract}
Objective: Acute kidney injury after cardiac surgery with cardiopulmonary bypass is closely related to systemic inflammatory reactions and oxidative stresses. Remote ischemic preconditioning is a systemic protective strategy whereby brief limb ischemia confers systemic protection against prolonged ischemia and inflammatory reactions in distant organs. This study investigated whether remote ischemic preconditioning provides systemic protective effect on kidneys that are not directly exposed to ischemia-reperfusion injury during complex valvular heart surgery.

Methods: Seventy-six adult patients undergoing complex valvular heart surgery were randomly assigned to either remote ischemic preconditioning group $(n=38)$ or control group $(n=38)$. Remote ischemic preconditioning consisted of 3 10-minute cycles of lower limb ischemia and reperfusion with an automated cuff inflator. Primary end points were comparisons of biomarkers of renal injury including serum creatinine, cystatin $\mathrm{C}$ and neutrophil gelatinase-associated lipocalin, and incidence of acute kidney injury. Secondary end points were comparisons of myocardial enzyme release and pulmonary parameters.
\end{abstract}

Results: There were no significant differences in serum levels of biomarkers of renal injury between groups throughout the study period. The incidence of acute kidney injury did not differ between groups. Creatine kinase isoenzyme MB at 24 hours after surgery was lower, and intensive care unit stay was shorter in the remote ischemic preconditioning group than in the control group.

Conclusions: In patients undergoing complex valvular heart surgery, remote ischemic preconditioning did not reduce degree of renal injury or incidence of acute kidney injury whereas it did reduce myocardial injury and intensive care unit stay. (J Thorac Cardiovasc Surg 2011;142:148-54)

Cardiac surgery with cardiopulmonary bypass $(\mathrm{CPB})$ is invariably accompanied by systemic inflammatory response and ischemia-reperfusion injury affecting multiple organs. Although during CPB and cardioplegic arrest the kidneys are under virtually continuous circulation, unlike the heart and lungs, decreased renal perfusion along with ineffective oxygen delivery system and high metabolic rate still make the kidneys vulnerable to ischemic injury. In conjunction, development of acute kidney injury (AKI) continues to be a common and serious complication, especially after complex valvular heart surgery requiring prolonged $\mathrm{CPB} .{ }^{1-3}$ Moreover, even minor postoperative AKI has been demonstrated to be associated with increased morbidity

From the Department of Anesthesiology and Pain Medicine and Anesthesia and Pain Research Institute, ${ }^{\mathrm{a}}$ Yonsei University College of Medicine, Seoul, Republic of Korea; the Department of Anesthesiology and Pain Medicine, ${ }^{\mathrm{b}}$ University of Soonchunhyang Cheonan Hospital, Cheonan, Republic of Korea; and Severance Biomedical Science Institute, ${ }^{\mathrm{c}}$ Seoul, Republic of Korea.

Disclosures: Authors have nothing to disclose with regard to commercial support.

Received for publication Feb 9, 2010; revisions received Oct 27, 2010; accepted for publication Nov 12, 2010; available ahead of print Jan 27, 2011.

Address for reprints: Young Lan Kwak, MD, PhD, Department of Anesthesiology and Pain Medicine and Anesthesia and Pain Research Institute, Yonsei University College of Medicine, 250 Seongsanno, Seodaemun-Ku, Seoul, Republic of Korea, 120-752 (E-mail: ylkwak@yuhs.ac).

$0022-5223 / \$ 36.00$

Copyright (c) 2011 by The American Association for Thoracic Surgery

doi:10.1016/j.jtcvs.2010.11.018 and mortality and a prolonged intensive care unit (ICU) stay, necessitating efforts to attenuate its development. ${ }^{4,5}$

Although the pathogenesis of AKI during CPB is complex, involving hemodynamic, oxidative and inflammatory mechanisms, remote ischemic preconditioning (RIPC) is a systemic protective strategy, whereby brief limb ischemia confers systemic protection against prolonged ischemia in distant organs. ${ }^{6,7}$ RIPC's effects are mediated through either humoral mediators or the recruitment of a neuronal pathway, with most evident beneficial effects observed on the myocardium, which is exposed to actual ischemiareperfusion injury during $\mathrm{CPB}{ }^{8,9}$ Although the kidneys are not directly exposed to ischemia-reperfusion injury, RIPC could exert renal protection through its systemic effect of attenuating the consequent activation of inflammatory cascade and production of oxygen free radicals. ${ }^{7}$ Evidence is limited, however, regarding the protective utility of limb RIPC against AKI in patients undergoing complex valvular heart surgery. We therefore investigated, in a prospective and randomized controlled trial, whether a limb RIPC protocol is effective in providing renal protection in patients with normal preoperative renal function undergoing complex valvular heart surgery.

\section{MATERIALS AND METHODS}

After approval of the institutional review board and procurement of informed consent, we studied 76 adult patients scheduled for elective, 


\author{
Abbreviations and Acronyms \\ AKI = acute kidney injury \\ $\mathrm{CK}-\quad=$ creatine kinase isoenzyme $\mathrm{MB}$ \\ MB \\ $\mathrm{CPB}=$ cardiopulmonary bypass \\ ICU = intensive care unit \\ NGAL $=$ neutrophil gelatinase-associated \\ lipocalin \\ Qs/Qt = Intrapulmonary shunt \\ RIPC $=$ remote ischemic preconditioning
}

complex valvular heart surgery, which was defined as double-valve surgery, combined valve and coronary artery bypass grafting procedures, Bentall operation, combined mitral valve surgery and tricuspid annuloplasty or reoperation between October 2008 and November 2009. We excluded patients older than 80 years and those with left main coronary artery disease greater than $50 \%$, hepatic or pulmonary disease, active infective endocarditis, left ventricular ejection fraction less than $30 \%$, myocardial infarction within 3 weeks, preexisting renal dysfunction (serum creatinine level $>1.6 \mathrm{mg} / \mathrm{dL}$ for men and $>1.4 \mathrm{mg} / \mathrm{dL}$ for women), or peripheral vascular disease affecting the lower limbs. In addition, patients taking the antidiabetic sulphonylurea glyburide (INN glibenclamide) or receiving nicorandil drug therapy were excluded because these agents have been shown to abolish preconditioning. ${ }^{10,11}$ Patients who required surgery for tricuspid valve replacement or hypothermic circulatory arrest were also excluded.

After induction of anesthesia, patients were randomly assigned to either the RIPC group $(\mathrm{n}=38)$ or the control group $(\mathrm{n}=38)$ by means of a computerized randomization table. RIPC consisted of 310 -minute cycles of lower limb ischemia induced by an automated cuff-inflator placed on the upper leg at an inflation pressure of $250 \mathrm{~mm} \mathrm{Hg}$ with an intervening $10 \mathrm{~min}$ utes of reperfusion during which the cuff was deflated. Control patients had a deflated cuff placed on the upper leg in place of RIPC application. Both cardiac surgeon and attending anesthesiologist were blinded to treatment allocation. There was at least a 10-minute interval between completion of the RIPC protocol and initiation of CPB.

All preoperative cardiac medications except diuretics were continued until the day of surgery. All patients received a standardized anesthetic management. In the operating room, standard monitoring devices were applied. Anesthesia was induced with intravenous midazolam $(0.03-0.07 \mathrm{mg} / \mathrm{kg})$, sufentanil (1.5-3.0 $\mu \mathrm{g} / \mathrm{kg})$, and rocuronium bromide $(0.9 \mathrm{mg} / \mathrm{kg})$ and maintained with sevoflurane $(0.8 \%-1.5 \%)$ and continuous infusion of sufentanil $(0.5-1.5 \mu \mathrm{g} /[\mathrm{kg} \cdot \mathrm{h}])$. After intubation, the lungs were ventilated at a tidal volume of $8 \mathrm{~mL} / \mathrm{kg}$, an inspiratory/expiratory time ratio of 1:2, and an inspiratory pause of $10 \%$ of total inspiration time in $40 \%$ oxygen with air and a positive end-expiratory pressure of $5 \mathrm{~cm} \mathrm{H}_{2} \mathrm{O}$. Respiratory rate was adjusted between 8 and 12 breaths/min to maintain normocarbia.

All patients received standardized surgical and CPB management with hemofiltration. CPB was instituted with a membrane oxygenator primed with $1200 \mathrm{~mL}$ of crystalloid solution, $200 \mathrm{~mL}$ of $20 \%$ mannitol, and $100 \mathrm{~mL}$ of $20 \%$ albumin. Surgical procedures were performed with patients under mild hypothermia $\left(32^{\circ} \mathrm{C}-33^{\circ} \mathrm{C}\right)$. Acid-base management was done with the $\alpha$-stat method, and the target range for $\mathrm{PaO}_{2}$ was 200 to $300 \mathrm{~mm} \mathrm{Hg}$. A nonpulsatile pump flow was maintained at a rate of 2.0 to $2.5 \mathrm{~L} /\left[\mathrm{min} \cdot \mathrm{m}^{2}\right]$, and blood cardioplegic solution was used. After the completion of the surgical procedure and systemic rewarming, patients were weaned from CPB. During the perioperative period, including $\mathrm{CPB}$, mean arterial pressure was maintained between 60 and $80 \mathrm{~mm} \mathrm{Hg}$. For vasopressor and inotropic support, norepinephrine and milrinone were used, respectively. Milrinone was used preferentially if the postbypass left ventricular ejection fraction was lower than $30 \%$, in case of evidence of right ventricular dysfunction, and in cases of pulmonary hypertension. Hemodynamic variables, including cardiac index, and the need for vasoactive drugs or inotropes were recorded 15 minutes after tracheal intubation (baseline, T1), 15 minutes after sternal closure (T2), and 12 and 24 hours after ICU arrival (T3 and T4). At the same time points, arterial blood was sampled. Intrapulmonary shunt $(\mathrm{Q} / \mathrm{Qt})$ was measured at $\mathrm{T} 1$ and $\mathrm{T} 2$. Qs/Qt was determined by the formula: Qs/ $\mathrm{Qt}=\left(\mathrm{CcO}_{2}-\mathrm{CaO}_{2}\right) /\left(\mathrm{CcO}_{2}-\mathrm{CvO}_{2}\right)$, where $\mathrm{CCO}_{2}$ represents capillary oxygen content, calculated assuming that pulmonary capillary $\mathrm{PO}_{2}$ is equal to alveolar $\mathrm{Po}_{2}, \mathrm{CaO}_{2}$ represents arterial oxygen content, and $\mathrm{CvO}_{2}$ represents venous oxygen content. Oxygen contents in arterial and mixed venous blood were calculated with the equations $\mathrm{CaO}_{2}=1.36 \cdot \mathrm{Hb} \cdot \mathrm{SaO}_{2}+0.0031 \cdot \mathrm{PaO}_{2}$ and $\mathrm{CvO}_{2}=1.36 \cdot \mathrm{Hb} \cdot \mathrm{SvO}_{2}+0.0031 \cdot \mathrm{Pvo}_{2}$, where $\mathrm{Hb}$ represents hemoglobin concentration (in grams per deciliter), $\mathrm{SaO}_{2}$ represents arterial oxygen saturation, $\mathrm{SvO}_{2}$ represents venous oxygen saturation, and $\mathrm{PvO}_{2}$ represents venous $\mathrm{Po}_{2}$.

The threshold for transfusion of packed red blood cells was hematocrit less than $20 \%$ during CPB or less than $25 \%$ after CPB. After heparin was reversed, the blood from the $\mathrm{CPB}$ circuit was salvaged (cell salvage device) and retransfused after sternal closure. Urinary output and all fluids (crystalloids, colloids, and blood products) administered to the patient were recorded until the second postoperative day. Blood glucose levels were strictly targeted between 80 and $150 \mathrm{mg} / \mathrm{dL}$ with insulin throughout the study period.

All patients were transferred to the ICU after surgery, where they received management according to institutional guidelines. Tracheal extubation was performed when hemodynamic condition was stable and the patient had adequate blood gas values while breathing spontaneously. Postoperative fluid therapy was performed as needed to keep pulmonary capillary wedge pressure between 10 and $14 \mathrm{~mm} \mathrm{Hg}$, cardiac index greater than $2 \mathrm{~L} /\left(\mathrm{min} \cdot \mathrm{m}^{2}\right)$, and urinary output greater than $0.5 \mathrm{~mL} /(\mathrm{kg} \cdot \mathrm{h})$. Patients with urinary output less than $30 \mathrm{~mL} / \mathrm{h}$ despite volume correction and maintenance of adequate cardiac and hemodynamic function were given intermittent doses of furosemide (5-40 mg every 3-4 hours). The durations of ventilation, stay in the ICU, and postoperative hospitalization were recorded.

\section{Biochemistry}

Serum creatinine levels were determined at least twice daily during the first 2 postoperative days and then daily during the hospital stay. Serum cystatin $\mathrm{C}$ was assessed 1 day before surgery, at ICU arrival, and at 24 and 48 hours after surgery. Blood samples were collected for measurement of plasma neutrophil gelatinase-associated lipocalin (NGAL) before induction of anesthesia, at ICU arrival, and 24 hours after surgery. Serum was separated from blood by centrifugation and stored at $-70^{\circ} \mathrm{C}$ until assay. Plasma NGAL level was detected by using a commercially available enzyme-linked immunosorbent assay kit (Human Lipocalin-2/NGAL Immunoassay; R\&D Systems, Inc, Minneapolis, Minn) according to manufacturer instructions. Estimated glomerular filtration rate was calculated by the Modification of Diet in Renal Disease formula as 186 . (serum creatinine level $\left.{ }^{-1.154}\right) \cdot\left(\right.$ age $\left.^{-0.203}\right) \cdot(0.742$ for female patients $) .{ }^{12}$ Creatine kinase isoenzyme MB (CK-MB) was assessed 1 day before surgery and at 12 and 24 hours after surgery.

\section{Study End Points}

The primary end point was to compare the serum biomarkers of renal injury and the incidence of AKI between groups. AKI was defined according to the Acute Kidney Injury Network criteria as an increase in serum creatinine level by either more than $50 \%$ or more than $0.3 \mathrm{mg} / \mathrm{dL}$ from baseline within 48 hours after surgery. ${ }^{13}$ The secondary end point was comparison of serum CK-MB levels at 12 and 24 hours after surgery.

\section{Statistical Analysis}

Data were analyzed with SPSS version 14.0 statistical software (SPSS Inc, an IBM Company, Chicago, Ill) and expressed as mean \pm SD or 


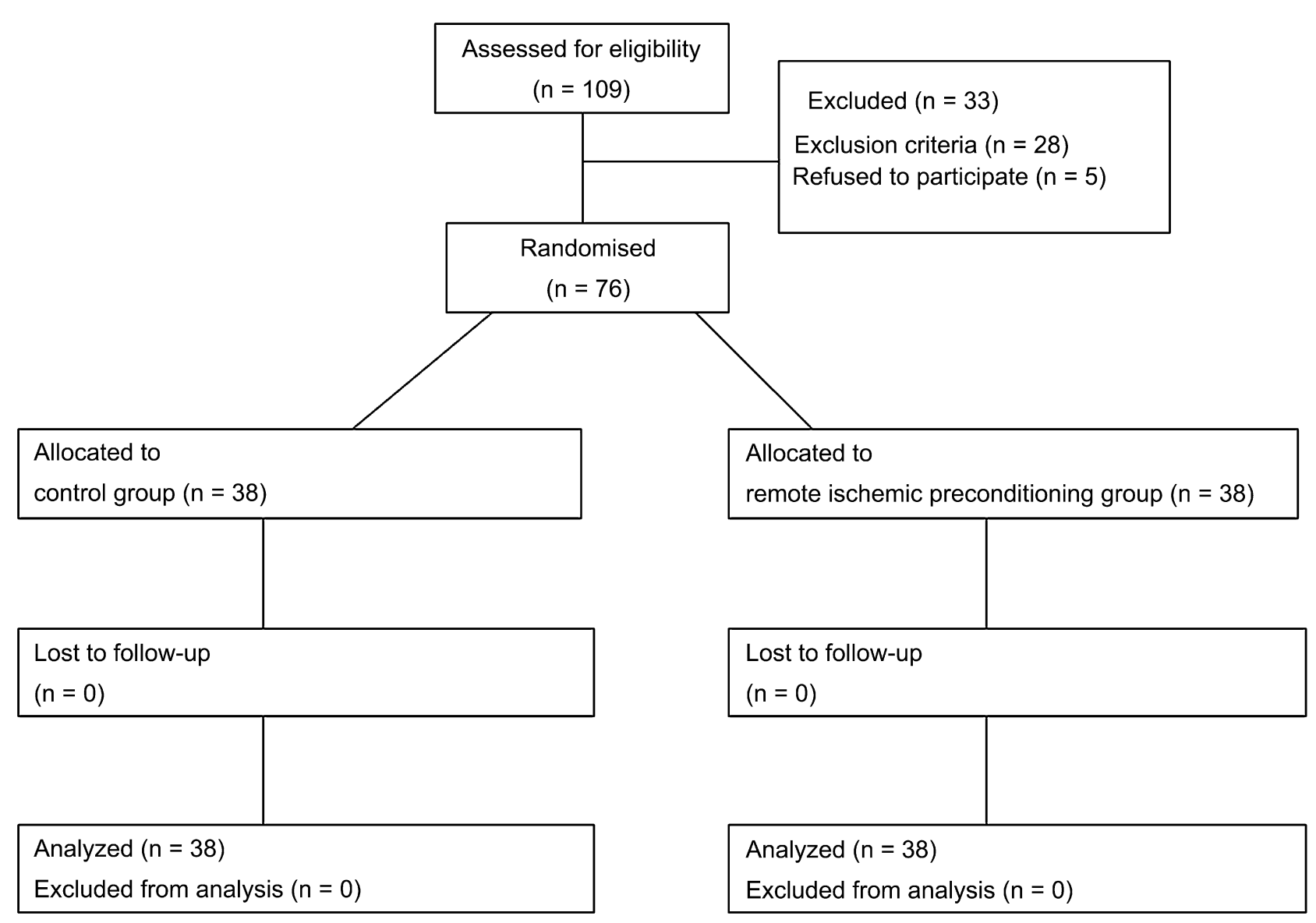

FIGURE 1. Diagram representing study cohort allocation.

number of patients. In the preliminary trial of 18 patients, the highest serum creatinine levels were $1.34 \pm 0.38$ and $1.01 \pm 0.35 \mathrm{mg} / \mathrm{dL}$ in the control and RIPC groups, respectively, within 48 hours after surgery. According to a preliminary study, we calculated that 38 patients would be required in each group for a $90 \%$ power to detect a $0.3-\mathrm{mg} / \mathrm{dL}$ difference in serum creatinine level between the groups with SD of $0.4 \mathrm{mg} / \mathrm{dL}$ and $\alpha$ level of .05 with an independent $t$ test. Data were compared between the groups with the $\chi^{2}$ test, Fisher's Exact test, independent $t$ test, or Mann-Whitney U test as appropriate. For intragroup comparisons of variables against baseline values, repeated measures analysis of variance followed by a post hoc Dunnett test was used.

\section{RESULTS}

One hundred nine patients were assessed for eligibility. Five patents declined to participate. Twenty-eight patients were excluded according to exclusion criteria. A total of 76 patients were randomly assigned (Figure 1). Patient characteristics were similar between the groups (Table 1). No local adverse effects related to the RIPC stimulus were observed.

The distributions of types of surgical procedures were similar between groups. Mean durations of CPB and aortic crossclamping and the numbers of patients with CPB lasting longer than 180 minutes were not different between the groups (Table 2). Total amounts of fluid infused and urinary outputs during the operation were similar between the groups. The numbers of patients and total amount of packed red blood cells transfused were similar between the groups during the study period. Urinary output showed a trend toward being higher during the first 24 hours after ICU admission in the RIPC group than in the control group (Table 2).

Hemodynamic variables, including cardiac index values and the numbers of patients requiring vasoactive drugs or inotropes, were not significantly different between the groups throughout the study period (Table 3). There were trends toward lower amounts of norepinephrine infused $(0.05 \pm 0.06$ vs $0.03 \pm 0.05 \mu \mathrm{g} /[\mathrm{kg} \cdot \min ], P=.072)$ and fewer patients requiring norepinephrine doses greater than $0.05 \mu \mathrm{g} /(\mathrm{kg} \cdot \mathrm{min})(16 \mathrm{vs} 9, P=.087)$ at T3 in the RIPC group relative to the control group. In intragroup comparisons of hemodynamic variables against baseline values, heart rates at T2, T3, and T4 were significantly increased in both groups. Mean arterial pressures at T2, mean pulmonary arterial pressures at $\mathrm{T} 3$ and $\mathrm{T} 4$, and pulmonary capillary wedge pressures at $\mathrm{T} 3$ and $\mathrm{T} 4$ were significantly decreased in both groups. Mean pulmonary arterial pressure and pulmonary capillary wedge pressure were significantly decreased at T2 in the control group. Central venous pressure at $\mathrm{T} 2$ and cardiac index values at $\mathrm{T} 2$ and $\mathrm{T} 4$ were significantly increased in the RIPC group. 
TABLE 1. Patient characteristics

\begin{tabular}{|c|c|c|c|}
\hline Variable & $\begin{array}{l}\text { Control } \\
(\mathbf{n}=\mathbf{3 8})\end{array}$ & $\begin{array}{c}\text { RIPC } \\
(\mathbf{n}=\mathbf{3 8})\end{array}$ & $\begin{array}{c}P \\
\text { value }\end{array}$ \\
\hline \multicolumn{4}{|l|}{ Age (y) } \\
\hline Mean $\pm \mathrm{SD}$ & $60 \pm 13$ & $57 \pm 12$ & .389 \\
\hline$>70$ (no.) & $7(18 \%)$ & $3(8 \%)$ & .175 \\
\hline Sex (male/female) & $15: 23$ & $15: 23$ & $>.999$ \\
\hline $\begin{array}{l}\text { Body surface area } \\
\qquad\left(\mathrm{m}^{2}, \text { mean } \pm \mathrm{SD}\right)\end{array}$ & $1.6 \pm 0.2$ & $1.7 \pm 0.1$ & .315 \\
\hline Diabetes (no.) & $4(11 \%)$ & $1(3 \%)$ & .165 \\
\hline Hypertension (no.) & $10(26 \%)$ & $8(21 \%)$ & .589 \\
\hline Atrial fibrillation (no.) & $21(55 \%)$ & $25(66 \%)$ & .348 \\
\hline $\begin{array}{l}\text { Left ventricular ejection } \\
\text { fraction }(\%, \text { mean } \pm \mathrm{SD})\end{array}$ & $60 \% \pm 12 \%$ & $63 \% \pm 9 \%$ & .357 \\
\hline \multicolumn{4}{|l|}{$\begin{array}{l}\text { Estimated glomerular filtration } \\
\text { rate }\left(\mathrm{mL} /\left[\mathrm{min} \cdot 1.73 \mathrm{~m}^{2}\right]\right)\end{array}$} \\
\hline Mean \pm SD & $78 \pm 16$ & $79 \pm 16$ & .891 \\
\hline$<60$ (no.) & $4(11 \%)$ & $4(11 \%)$ & $>.999$ \\
\hline \multicolumn{4}{|l|}{ Preoperative medications (no.) } \\
\hline Digoxin & $18(47 \%)$ & $14(37 \%)$ & .353 \\
\hline ACE-I or ARB & $18(47 \%)$ & $16(42 \%)$ & .645 \\
\hline Calcium-channel blocker & $5(13 \%)$ & $7(18 \%)$ & .529 \\
\hline$\beta$-Blockers & $6(16 \%)$ & $9(24 \%)$ & .387 \\
\hline Diuretics & $25(66 \%)$ & $26(68 \%)$ & .807 \\
\hline Statins & $4(11 \%)$ & $2(5 \%)$ & .674 \\
\hline NYHA functional class III or IV (no.) & $8(21 \%)$ & $6(16 \%)$ & .554 \\
\hline EuroSCORE $($ mean $\pm \mathrm{SD})$ & $3.5 \pm 2.4$ & $3.1 \pm 1.4$ & .368 \\
\hline
\end{tabular}

$R I P C$, Remote ischemic preconditioning; $A C E-I$, angiotensin-converting enzyme inhibitor; $A R B$, angiotensin receptor blocker; $N Y H A$, New York Heart Association.

There were no differences in $\mathrm{Qs} / \mathrm{Qt}, \mathrm{PaO}_{2} /$ inspired oxygen fraction ratio, and alveolar-arterial oxygen gradient between the groups during perioperative period. In intragroup comparisons of respiratory variables against baseline values, Qs/Qt values at T2 and alveolar-arterial oxygen gradients at $\mathrm{T} 2$ were significantly increased in both groups. $\mathrm{PaO}_{2} /$ inspired oxygen fraction ratios at $\mathrm{T} 2$ and T3 were significantly decreased in both groups (Table 3).

There were no significant differences in serum levels of creatinine, cystatin C, or NGAL or in estimated glomerular filtration rate between the groups throughout the study period. Highest serum creatinine levels were observed within the first 3 postoperative days in all patients. Serum creatinine levels were increased and estimated glomerular filtration rates were decreased relative to their respective baseline values at postoperative days 1 and 2 in both groups. Plasma NGAL levels were increased relative to their respective baseline values after surgery throughout the postoperative period in both groups. Intragroup comparisons of serum cystatin C levels revealed no significant differences at all time points of measurements in both groups relative to the respective baseline values of each group. AKI occurred in $34 \%(n=26)$ of all patients, the incidences of AKI did not differ between the groups, and none of the patients required hemodialysis (Table 4). CK-MB was significantly lower at 24 hours after
TABLE 2. Operative details and perioperative fluid balance and transfusion

\begin{tabular}{|c|c|c|c|}
\hline Variable & $\begin{array}{l}\text { Control } \\
(\mathbf{n}=38)\end{array}$ & $\begin{array}{c}\text { RIPC } \\
(\mathbf{n}=\mathbf{3 8})\end{array}$ & $\begin{array}{c}P \\
\text { value }\end{array}$ \\
\hline $\begin{array}{l}\text { Duration of aortic crossclamp } \\
\quad(\text { min, mean } \pm \mathrm{SD})\end{array}$ & $108 \pm 29$ & $98 \pm 27$ & .122 \\
\hline \multicolumn{4}{|c|}{ Duration of cardiopulmonary bypass (min) } \\
\hline Mean \pm SD & $145 \pm 42$ & $132 \pm 34$ & .144 \\
\hline$>180$ (no.) & $7(18 \%)$ & $5(13 \%)$ & .529 \\
\hline \multicolumn{4}{|l|}{ Procedures (no.) } \\
\hline Concomitant valve or CABG & $7(18 \%)$ & $2(5 \%)$ & .153 \\
\hline Multiple valve surgery & $21(55 \%)$ & $17(45 \%)$ & .359 \\
\hline Bentall procedure & $2(5 \%)$ & $4(11 \%)$ & 674 \\
\hline Mitral valve replacement & $4(11 \%)$ & $9(24 \%)$ & .128 \\
\hline Mitral valve reconstruction & $3(8 \%)$ & $2(5 \%)$ & $>.999$ \\
\hline Previous cardiac surgery & $11(29 \%)$ & $13(34 \%)$ & .622 \\
\hline \multicolumn{4}{|l|}{ Input and output during operation } \\
\hline Crystalloid (mL, mean $\pm \mathrm{SD}$ ) & $2290 \pm 1076$ & $2130 \pm 1032$ & .528 \\
\hline Colloid $(\mathrm{mL}$, mean $\pm \mathrm{SD})$ & $786 \pm 467$ & $944 \pm 1179$ & .458 \\
\hline Urinary output $(\mathrm{mL}$, mean $\pm \mathrm{SD})$ & $1239 \pm 609$ & $1229 \pm 609$ & .943 \\
\hline $\begin{array}{l}\text { PRBCs transfused } \\
\quad \text { (units, mean } \pm \mathrm{SD})\end{array}$ & $1.3 \pm 1.5$ & $1.0 \pm 1.5$ & .358 \\
\hline \multicolumn{4}{|l|}{ Fluid input $(\mathrm{mL}$, mean $\pm \mathrm{SD})$} \\
\hline At ICU $0-24 \mathrm{~h}$ & $4205 \pm 892$ & $4252 \pm 1094$ & .84 \\
\hline At ICU $24-48 \mathrm{~h}$ & $2653 \pm 825$ & $2441 \pm 1051$ & .347 \\
\hline \multicolumn{4}{|l|}{ Urinary output $(\mathrm{mL}$, mean $\pm \mathrm{SD}$ ) } \\
\hline At ICU $0-24 \mathrm{~h}$ & $3134 \pm 688$ & $3512 \pm 1063$ & .069 \\
\hline At ICU $24-48 \mathrm{~h}$ & $2449 \pm 729$ & $2745 \pm 1085$ & .306 \\
\hline \multicolumn{4}{|c|}{ PRBCs transfused (units, mean $\pm \mathrm{SD}$ ) } \\
\hline At ICU 0-24 h & $0.4 \pm 1.1$ & $0.9 \pm 2.1$ & .205 \\
\hline At ICU $24-48 \mathrm{~h}$ & $0.2 \pm 0.7$ & $0.1 \pm 0.4$ & .512 \\
\hline
\end{tabular}

RIPC, Remote ischemic preconditioning; $C A B G$, coronary artery bypass grafting; $P R B C S$, packed red blood cells; $I C U$, intensive care unit.

surgery in the RIPC group than in the control group $(32.0 \pm 19.1$ vs $23.4 \pm 9.1 \mathrm{ng} / \mathrm{mL}, P=.017)$.

Postoperative stay in the ICU was significantly shorter in the RIPC group than in the control group. The times to extubation and postoperative hospitalizations were similar between the groups (Table 5).

\section{DISCUSSION}

In this prospective, randomized trial addressing the renal protective effects of lower limb RIPC in patients undergoing complex valvular heart surgery, we could not observe any beneficial effects in terms of serum biomarkers for renal injury and AKI development. RIPC was however, associated with significantly lower CK-MB level at 24 hours after surgery and with shorter stay in the ICU than in the control group.

AKI after cardiac surgery is associated with a high mortality and more complicated postoperative course. It occurs in as many as $40 \%$ of all patients after cardiac surgery, depending on the specific definition, with $1 \%$ to $3 \%$ requiring renal replacement therapy., ${ }^{2,14,15}$ Despite advances in CPB techniques, the incidence of AKI after cardiac 
TABLE 3. Hemodynamic and respiratory variables and numbers of patients requiring vasoactive drugs

\begin{tabular}{|c|c|c|c|c|}
\hline Variables & T1 & $\mathbf{T 2}$ & T3 & T4 \\
\hline \multicolumn{5}{|c|}{ Heart rate (beats/min, mean $\pm \mathrm{SD}$ ) } \\
\hline Control & $65 \pm 10$ & $84 \pm 13^{*}$ & $83 \pm 10^{*}$ & $83 \pm 10^{*}$ \\
\hline RIPC & $67 \pm 15$ & $82 \pm 11^{*}$ & $80 \pm 10^{*}$ & $81 \pm 14^{*}$ \\
\hline \multicolumn{5}{|c|}{ Mean arterial pressure $(\mathrm{mm} \mathrm{Hg}$, mean $\pm \mathrm{SD})$} \\
\hline Control & $76 \pm 10$ & $66 \pm 8^{*}$ & $76 \pm 9$ & $74 \pm 7$ \\
\hline RIPC & $80 \pm 11$ & $67 \pm 9^{*}$ & $77 \pm 11$ & $75 \pm 11$ \\
\hline \multicolumn{5}{|c|}{ Mean pulmonary arterial pressure $(\mathrm{mm} \mathrm{Hg}$, mean $\pm \mathrm{SD})$} \\
\hline Control & $25 \pm 7$ & $22 \pm 3^{*}$ & $20 \pm 4 *$ & $18 \pm 5^{*}$ \\
\hline RIPC & $23 \pm 6$ & $22 \pm 6$ & $19 \pm 4^{*}$ & $20 \pm 5^{*}$ \\
\hline \multicolumn{5}{|c|}{ Central venous pressure $(\mathrm{mm} \mathrm{Hg}$, mean $\pm \mathrm{SD})$} \\
\hline Control & $10 \pm 2$ & $10 \pm 2$ & $9 \pm 2$ & $8 \pm 3$ \\
\hline RIPC & $9 \pm 3$ & $11 \pm 2^{*}$ & $8 \pm 2$ & $8 \pm 3$ \\
\hline \multicolumn{5}{|c|}{ Pulmonary capillary wedge pressure $(\mathrm{mm} \mathrm{Hg}$, mean $\pm \mathrm{SD})$} \\
\hline Control & $19 \pm 6$ & $16 \pm 2^{*}$ & $15 \pm 3 *$ & $13 \pm 4^{*}$ \\
\hline RIPC & $18 \pm 5$ & $16 \pm 2$ & $15 \pm 3^{*}$ & $14 \pm 4^{*}$ \\
\hline \multicolumn{5}{|c|}{ Cardiac index $\left(\mathrm{L} /\left[\mathrm{min} \cdot \mathrm{m}^{2}\right]\right.$, mean $\left.\pm \mathrm{SD}\right)$} \\
\hline Control & $2.5 \pm 0.6$ & $3.0 \pm 0.7$ & $2.9 \pm 0.5$ & $3.2 \pm 0.7$ \\
\hline RIPC & $2.3 \pm 0.5$ & $2.8 \pm 0.5^{*}$ & $2.6 \pm 0.6$ & $3.1 \pm 0.5^{*}$ \\
\hline \multicolumn{5}{|c|}{ Pulmonary shunt fraction $(\%$, mean \pm SD $)$} \\
\hline Control & $13.4 \pm 6.6$ & $38.6 \pm 12.5^{*}$ & & \\
\hline RIPC & $12.9 \pm 11.5$ & $34.0 \pm 25.6^{*}$ & & \\
\hline \multicolumn{5}{|c|}{$\mathrm{PaO}_{2} / \mathrm{FiO}_{2}($ mean $\pm \mathrm{SD})$} \\
\hline Control & $456 \pm 102$ & $354 \pm 128^{*}$ & $370 \pm 95^{*}$ & $406 \pm 190$ \\
\hline RIPC & $484 \pm 110$ & $393 \pm 125^{*}$ & $371 \pm 89^{*}$ & $437 \pm 106$ \\
\hline \multicolumn{5}{|c|}{$\mathrm{PAO}_{2}-\mathrm{PaO}_{2}(\mathrm{~mm} \mathrm{Hg}$, mean $\pm \mathrm{SD})$} \\
\hline Control & $62 \pm 39$ & $124 \pm 86^{*}$ & $105 \pm 78$ & $82 \pm 84$ \\
\hline RIPC & $62 \pm 41$ & $97 \pm 71 *$ & $105 \pm 66$ & $52 \pm 41$ \\
\hline \multicolumn{5}{|c|}{ Norepinephrine (no.) } \\
\hline Control & 0 & $26(68 \%)$ & $14(37 \%)$ & $10(26 \%)$ \\
\hline RIPC & 0 & $20(53 \%)$ & $10(26 \%)$ & $10(26 \%)$ \\
\hline \multicolumn{5}{|c|}{ Milrinone (no.) } \\
\hline Control & 0 & $13(34 \%)$ & $16(42 \%)$ & $17(45 \%)$ \\
\hline RIPC & 0 & $10(26 \%)$ & $19(50 \%)$ & $13(34 \%)$ \\
\hline
\end{tabular}

$T 1,15$ minutes after tracheal intubation; $T 2,15$ minutes after sternum closure; $T 3,12$ hours after arrival at intensive care unit; $T 4,24$ hours after arrival at intensive care unit; RIPC, remote ischemic preconditioning; $\mathrm{FiO}_{2}$, inspired oxygen fraction; $\mathrm{PAO}_{2}$ $-\mathrm{PaO}_{2}$, alveolar-arterial oxygen gradient. $* P<.05$ versus baseline (T1) in each group.

surgery has remained unchanged or has even slightly increased. ${ }^{16}$ Mortality among patients with AKI has decreased with time with advances in practices of dialysis care, although it is unchanged in those with multiple organ dysfunctions. ${ }^{16}$ Even minor postoperative increases in serum creatinine from preoperative baseline are associated with increases in duration of ICU stay and short-term mortality. ${ }^{4,5}$ The incidence of AKI is affected not only by preoperative renal function but also by age, insulindependent diabetes, impaired left ventricular function, congestive heart failure, and particular types of cardiac surgery. ${ }^{1,3,17}$ Among various cardiac surgical procedures, risk of postoperative AKI is increased with valvular heart surgery, especially double aortic and mitral valve surgery, mitral valve involved procedure, reoperation, and concomitant coronary artery bypass grafting. ${ }^{2,3}$ In
TABLE 4. Changes in renal biomarkers

\begin{tabular}{|c|c|c|c|}
\hline Variable & $\begin{array}{l}\text { Control } \\
(\mathrm{n}=38) \\
\end{array}$ & $\begin{array}{c}\text { RIPC } \\
(n=38)\end{array}$ & $\begin{array}{c}P \\
\text { value }\end{array}$ \\
\hline Acute kidney injury (no.) & $12(32)$ & $14(37)$ & .688 \\
\hline \multicolumn{4}{|l|}{ Creatinine $(\mathrm{mg} / \mathrm{dL}$, mean $\pm \mathrm{SD})$} \\
\hline Baseline & $0.92 \pm 0.17$ & $0.91 \pm 0.16$ & .871 \\
\hline ICU arrival & $0.87 \pm 0.19$ & $0.90 \pm 0.24$ & .567 \\
\hline POD 1 & $1.07 \pm 0.24$ & $1.19 \pm 0.38$ & .094 \\
\hline POD 2 & $1.11 \pm 0.27$ & $1.10 \pm 0.35$ & .81 \\
\hline POD 3 & $0.99 \pm 0.26$ & $0.98 \pm 0.31$ & .904 \\
\hline Maximum within POD 3 & $1.19 \pm 0.25$ & $1.24 \pm 0.36$ & .444 \\
\hline Change from baseline $(\%)$ & $31 \% \pm 23 \%$ & $37 \% \pm 32 \%$ & .36 \\
\hline \multicolumn{4}{|c|}{ Cystatin C (mg/L, mean $\pm \mathrm{SD})$} \\
\hline Baseline & $0.86 \pm 0.23$ & $0.84 \pm 0.18$ & .67 \\
\hline ICU arrival & $0.96 \pm 0.21$ & $0.96 \pm 0.20$ & .981 \\
\hline $24 \mathrm{~h}$ after surgery & $0.84 \pm 0.28$ & $0.84 \pm 0.32$ & .958 \\
\hline $48 \mathrm{~h}$ after surgery & $0.91 \pm 0.32$ & $0.88 \pm 0.34$ & .508 \\
\hline Maximum within $48 \mathrm{~h}$ & $0.97 \pm 0.32$ & $0.92 \pm 0.36$ & .357 \\
\hline \multicolumn{4}{|c|}{ Plasma neutrophil gelatinase-associated lipocalin $(\mathrm{ng} / \mathrm{mL}$, mean $\pm \mathrm{SD})$} \\
\hline Baseline & $49.5 \pm 20.6$ & $50.6 \pm 14.0$ & .595 \\
\hline ICU arrival & $255.0 \pm 121.6$ & $272.4 \pm 99.7$ & .548 \\
\hline $24 \mathrm{~h}$ after surgery & $224.8 \pm 110.2$ & $240.1 \pm 138.0$ & .805 \\
\hline \multicolumn{4}{|c|}{ Estimated glomerular filtration rate $\left(\mathrm{mL} /\left[\mathrm{min} \cdot 1.73 \mathrm{~m}^{2}\right]\right.$, mean $\left.\pm \mathrm{SD}\right)$} \\
\hline ICU arrival & $84 \pm 18$ & $82 \pm 20$ & .737 \\
\hline POD 1 & $67 \pm 17$ & $62 \pm 20$ & .206 \\
\hline POD 2 & $65 \pm 18$ & $68 \pm 22$ & .461 \\
\hline POD 3 & $74 \pm 22$ & $77 \pm 22$ & 699 \\
\hline
\end{tabular}

$R I P C$, Remote ischemic preconditioning; $I C U$, intensive care unit; $P O D$, postoperative day.

these complex valvular heart procedures requiring prolonged $\mathrm{CPB}$, various conditions including $\mathrm{CPB}-$ induced activation of inflammatory pathways, decreased renal perfusion, and production of emboli and nephrotoxins contribute to development of AKI. Recent evidences suggest that avoidance of excessive hemodilution and transfusion, appropriate fluid management, maintenance of tight glucose control with insulin, and the use of pulsatile flow were only potential renal protective therapies, and no interventions have demonstrated conclusive efficacy for the prevention of AKI. ${ }^{1,18,19}$

RIPC is a protective strategy whereby brief limb ischemia confers systemic protection against prolonged ischemia in distant organs through either humoral mediators or the recruitment of a neuronal pathway. ${ }^{6,7}$ Although most of the previous studies addressing RIPC have focused on the protection of organs undergoing direct ischemiareperfusion injury, such as the heart and lungs in cardiac surgery with CPB and kidneys in aortic surgery, RIPC is a systemic protective strategy. ${ }^{8,9,20,21}$ RIPC attenuates the systemic inflammatory response through activation of a favorable profile of gene transcription that is both antiinflammatory and antiapoptotic. ${ }^{22,23}$ RIPC modifies gene expression involved in cytokine synthesis; leukocyte chemotaxis, adhesion, migration, and exocytosis; innate 
TABLE 5. Postoperative outcome data

\begin{tabular}{lccc}
\hline \multicolumn{1}{c}{ Variable } & $\begin{array}{c}\text { Control } \\
(\mathbf{n}=\mathbf{3 8})\end{array}$ & $\begin{array}{c}\text { RIPC } \\
(\mathbf{n}=\mathbf{3 8})\end{array}$ & $\begin{array}{c}\boldsymbol{P} \\
\text { value }\end{array}$ \\
\hline Reoperation for bleeding (no.) & $4(11 \%)$ & $1(3 \%)$ & .2 \\
Reintubation (no.) & $1(3 \%)$ & 0 & .493 \\
Time on ventilator (h, mean $\pm \mathrm{SD})$ & $18.9 \pm 14.9$ & $16.8 \pm 9.4$ & .456 \\
Intensive care unit stay (d, mean $\pm \mathrm{SD})$ & $3.4 \pm 1.4$ & $2.7 \pm 0.7 *$ & .013 \\
Postoperative hospital stay & $12.0 \pm 6.1$ & $11.1 \pm 3.4$ & .435 \\
$\quad(\mathrm{~d}$, mean \pm SD) & & & \\
\hline$R I P C$, Remote ischemic preconditioning. $* P<.05$ versus control group. &
\end{tabular}

immunity signaling pathways; and apoptosis in human beings within 15 minutes, and more so after 24 hours. ${ }^{22}$ In clinical studies, RIPC mitigated CPB-induced systemic inflammatory response syndrome, as shown by the increased variance of interleukin 10 levels and reduced variance of tumor necrosis factor $\alpha$ levels in cardiac surgery. ${ }^{23}$ We therefore hypothesized that this systemic anti-inflammatory suppression might reduce the severity or development of CPB-associated renal injury because of the multiple factors involved in the pathogenesis. ${ }^{22}$ RIPC's obvious advantages of noninvasive nature, absence of cost, and ease of application without interrupting operation were also considered more advantageous than other interventions for clinical application.

In contrast to our expectation, RIPC did not attenuate the increase in serum biomarkers of renal injury in this study, although it was associated with increased early postoperative urinary output with similar use of diuretics. In this study, we assessed renal injury with plasma NGAL and serum cystatin $\mathrm{C}$, which have been reported as sensitive, specific, and highly predictive early biomarkers for AKI, ${ }^{14,24,25}$ as well as serum creatinine. Early postoperative measurement of plasma NGAL has been reported to be valuable for identifying AKI independent of preoperative renal function. ${ }^{24}$ Although serum creatinine has been used as a biomarker of diagnosis of AKI in numerous clinical studies, serum creatinine is a late indicator of AKI because it does not accurately depict renal function until a steady state has been reached, taking several days when about half of the renal function has already been lost. ${ }^{22}$ In addition, serum creatinine may be affected by obligatory CPB-related volume expansion in patients undergoing cardiac surgery, resulting in a fall in serum creatinine despite the presence of significant renal injury. We therefore assessed plasma NGAL and serum cystatin C until 24 and 48 hours after the surgery, respectively, and serum creatinine until hospital discharge. Still no benefits were observed. The duration of ischemia, the area under ischemia, and number of cycles of RIPC used in this study were almost maximal compared with previous studies and thus should not have affected the results.

RIPC did, however, reduce elevation of myocardial enzyme levels, which was our secondary end point, and a trend was seen toward reduced postoperative vasopressor require- ments with significantly shortened duration of ICU stay. Plausible causes for the observations of this trial may be that RIPC is more effective in protecting organs enduring direct and obvious ischemia-reperfusion insult, resulting in organ damage associated with marked proinflammatory and oxidative stress. RIPC has exerted cardiac and lung protective effects in several clinical studies with aortic crossclamping and has shown renal protective effects in major vascular surgery or interventions without perfusion to the kidneys. $^{20,23,26}$ Differences in mechanisms involved in cardiac and renal protection conferred by RIPC may also have affected the difference between the heart and kidney with respect to RIPC protection. RIPC showed a biphasic pattern of protection. An early phase is believed to act within a few minutes to 2 to 4 hours after RIPC and mediated by opening of mitochondrial adenosine triphosphate-sensitive potassium channels. ${ }^{22,27}$ Early phase is independent of protein synthesis and continues into a later phase. A delayed second window of protection occurs at 24 to 72 hours and is probably the result of modified gene expression and protein synthesis. The antiinflammatory gene responses were significantly downregulated at 15 minutes after termination of RIPC and then markedly amplified at 24 hours. ${ }^{22}$ Reduction of CK-MB at 24 hours after surgery in the RIPC group in this study may be attributable to the late phase effect of remote protection. Moreover, vasopressor requirement after CPB may closely reflect increased systemic inflammatory responserelated vasoplegia. The results of this study thus seem to demonstrate a certain clinical utility of RIPC for patients undergoing complex valvular heart surgery despite the lack of renal protective effect.

The limitations of this study are as follows. Although we measured reliable biomarkers of renal injury, we did not measure inflammatory mediators related to CPB. Thus we could not delineate the association between the lack of renal protective effect of RIPC and the individual degree of systemic inflammatory response. Also, the numbers of patients with diabetes and those undergoing reoperation for postoperative bleeding were higher in the control group, which may have confounded the results even though the differences were not statistically significant. The number of patients involved was determined on the basis of the postoperative serum creatinine levels to evaluate the effect of RIPC on postoperative renal function, and thus this study might be underpowered to detect the effect of RIPC on the incidence of postoperative AKI.

In conclusion, RIPC mediated by transient lower limb ischemia did not exert renal protective effects in patients undergoing complex valvular heart surgery without preexisting renal insufficiency. The beneficial effects of RIPC seem to be more prominent in organs directly affected by ischemia-reperfusion injury, as demonstrated by reduced release of myocardial enzyme. 


\section{References}

1. Stafford-Smith M, Patel UD, Phillips-Bute BG, Shaw AD, Swaminathan M Acute kidney injury and chronic kidney disease after cardiac surgery. $A d v$ Chronic Kidney Dis. 2008;15:257-77.

2. Rahmanian PB, Filsoufi F, Castillo JG, Zaku B, Chikwe J, Carpentier A, et al. Predicting postoperative renal failure requiring dialysis, and an analysis of long-term outcome in patients undergoing valve surgery. $J$ Heart Valve Dis. 2008; 17:657-65.

3. Mehta RH, Grab JD, O'Brien SM, Bridges CR, Gammie JS, Haan CK, et al. Bedside tool for predicting the risk of postoperative dialysis in patients undergoing cardiac surgery. Circulation. 2006;114:2208-16.

4. Lassnigg A, Schmidlin D, Mouhieddine M, Bachmann LM, Druml W, Bauer P, et al. Minimal changes of serum creatinine predict prognosis in patients after cardiothoracic surgery: a prospective cohort study. J Am Soc Nephrol. 2004;15: 1597-605.

5. Ryckwaert F, Boccara G, Frappier JM, Colson PH. Incidence, risk factors, and prognosis of a moderate increase in plasma creatinine early after cardiac surgery. Crit Care Med. 2002;30:1495-8.

6. Gho BC, Schoemaker RG, van den Doel MA, Duncker DJ, Verdouw PD. Myocardial protection by brief ischemia in noncardiac tissue. Circulation. 1996;94:2193-200

7. Hausenloy DJ, Yellon DM. Remote ischaemic preconditioning: underlying mechanisms and clinical application. Cardiovasc Res. 2008;79:377-86.

8. Walsh SR, Tang T, Sadat U, Dutka DP, Gaunt ME. Cardioprotection by remote ischaemic preconditioning. Br J Anaesth. 2007;99:611-6.

9. Hausenloy DJ, Mwamure PK, Venugopal V, Harris J, Barnard M, Grundy E, et al. Effect of remote ischaemic preconditioning on myocardial injury in patients undergoing coronary artery bypass graft surgery: a randomised controlled trial. Lancet. 2007;370:575-9.

10. Mocanu MM, Maddock HL, Baxter GF, Lawrence CL, Standen NB, Yellon DM. Glimepiride, a novel sulfonylurea, does not abolish myocardial protection afforded by either ischemic preconditioning or diazoxide. Circulation. 2001;103: 3111-6.

11. Loubani M, Galiñanes M. Long-term administration of nicorandil abolishes ischemic and pharmacologic preconditioning of the human myocardium: role of mitochondrial adenosine triphosphate-dependent potassium channels. J Thorac Cardiovasc Surg. 2002;124:750-7.

12. Levey AS, Bosch JP, Lewis JB, Greene T, Rogers N, Roth D. A more accurate method to estimate glomerular filtration rate from serum creatinine: A new prediction equation. Modification of Diet in Renal Disease Study Group. Ann Intern Med. 1999;130:461-70.

13. Mehta RL, Kellum JA, Shah SV, Molitoris BA, Ronco C, Warnock DG, et al. Acute Kidney Injury Network: report of an initiative to improve outcomes in acute kidney injury. Crit Care. 2007;11:R31.
14. Haase M, Bellomo R, Devarajan P, Ma Q, Bennett MR, Möckel M, et al. Novel biomarkers early predict the severity of acute kidney injury after cardiac surgery in adults. Ann Thorac Surg. 2009;88:124-30.

15. Wagener G, Gubitosa G, Wang S, Borregaard N, Kim M, Lee HT. Urinary neutrophil gelatinase-associated lipocalin and acute kidney injury after cardiac surgery. Am J Kidney Dis. 2008;52:425-33.

16. Thakar CV, Worley S, Arrigain S, Yared JP, Paganini EP. Improved survival in acute kidney injury after cardiac surgery. Am J Kidney Dis. 2007;50:703-11.

17. Shahian DM, O'Brien SM, Filardo G, Ferraris VA, Haan CK, Rich JB, et al. The Society of Thoracic Surgeons 2008 cardiac surgery risk models: part 3-valve plus coronary artery bypass grafting surgery. Ann Thorac Surg. 2009;88(1 Suppl):S43-62.

18. Tolwani A, Paganini E, Joannidis M, Zamperetti N, Verbine A, Vidyasagar V, et al. Treatment of patients with cardiac surgery associated-acute kidney injury. Int J Artif Organs. 2008;31:190-6.

19. Lecomte P, Van Vlem B, Coddens J, Cammu G, Nollet G, Nobels F, et al. Tight perioperative glucose control is associated with a reduction in renal impairment and renal failure in non-diabetic cardiac surgical patients. Crit Care. 2008;12:R154.

20. Ali ZA, Callaghan CJ, Lim E, Ali AA, Nouraei SA, Akthar AM, et al. Remote ischemic preconditioning reduces myocardial and renal injury after elective abdominal aortic aneurysm repair: a randomized controlled trial. Circulation. 2007; 116(11 Suppl):I98-105.

21. Walsh SR, Boyle JR, Tang TY, Sadat U, Cooper DG, Lapsley M, et al. Remote ischemic preconditioning for renal and cardiac protection during endovascular aneurysm repair: a randomized controlled trial. J Endovasc Ther. 2009;16:680-9.

22. Konstantinov IE, Arab S, Kharbanda RK, Li J, Cheung MM, Cherepanov V, et al. The remote ischemic preconditioning stimulus modifies inflammatory gene expression in humans. Physiol Genomics. 2004;19:143-50.

23. Cheung MM, Kharbanda RK, Konstantinov IE, Shimizu M, Frndova H, Li J, et al. Randomized controlled trial of the effects of remote ischemic preconditioning on children undergoing cardiac surgery: first clinical application in humans. $J A m$ Coll Cardiol. 2006;47:2277-82.

24. Haase-Fielitz A, Bellomo R, Devarajan P, Story D, Matalanis G, Dragun D, et al. Novel and conventional serum biomarkers predicting acute kidney injury in adult cardiac surgery—a prospective cohort study. Crit Care Med. 2009;37:553-60.

25. Cruz DN, Ronco C, Katz N. Neutrophil gelatinase-associated lipocalin: a promising biomarker for detecting cardiac surgery-associated acute kidney injury. J Thorac Cardiovasc Surg. 2010;139:1101-6.

26. Zhou W, Zeng D, Chen R, Liu J, Yang G, Liu P, et al. Limb ischemic preconditioning reduces heart and lung injury after an open heart operation in infants. Pediatr Cardiol. 2009;31:22-9.

27. Loukogeorgakis SP, Williams R, Panagiotidou AT, Kolvekar SK, Donald A, Cole TJ, et al. Transient limb ischemia induces remote preconditioning and remote postconditioning in humans by a K(ATP)-channel dependent mechanism. Circulation. 2007;116:1386-95. 